\title{
Emprego, estratificação e desigualdade
}

\author{
JOSÉ ALCIDES FIGUEIREDO SANTOS ${ }^{I}$ \\ e LUIZ VICENTE FONSECA RIBEIRO ${ }^{I I}$
}

S RELAÇÕES entre divisão social do trabalho e estratificação social for-
mam nexos explicativos-chave da desigualdade de renda no Brasil. As
divisões de classe social inscritas na estrutura do emprego compõem o cenário principal deste artigo, ao nortearem a interpretação das mudanças na desigualdade de renda no período recente, ao qual se agregam os grupos de status (gênero e raça), os fatores de segmentação ou diferenciação econômica e as credenciais educacionais. Sustenta-se que as mudanças de renda associadas aos determinantes em questão permitem captar alterações em dimensões socialmente organizadas da distribuição das recompensas. Teorias e conceitos sociológicos servem ao propósito de introduzir as relações sociais entre grupos no espaço de definição e mensuração da desigualdade. Prioriza-se o delineamento dos determinantes de resultados em vez de se concentrar no retrato descritivo dos resultados distributivos em si. A desigualdade preexistente na distribuição de recursos valiosos estrutura socialmente a ocorrência de oportunidades e resultados desiguais. Os recursos mobilizados funcionam como meios ou bases do exercício de poder social e da obtenção de vantagens nas relações entre indivíduos e grupos sociais.

As classes sociais representam princípios de divisão, categorias ou posições no mundo social que afetam o poder social e as chances de vida dos seus ocupantes. As abordagens de classe baseadas no controle de ativos especificam os tipos de recursos e as relações sociais correspondentes que geram as divisões existentes. As divisões de classe são constituídas por desigualdades de poderes e direitos sobre ativos geradores de valor que produzem vantagens e desvantagens entre categorias. Ativos geradores de valor são recursos mobilizáveis que possuem o potencial de aumentar o valor transferível de bens e serviços. Os recursos geram benefícios para os controladores e receptores quando usados para produzir valor adicional inserindo-se em formas coordenadas de trabalho e combinando-se com outros recursos. As relações de propriedade e poder na sociedade capitalista geram formas de desigualdade estruturada e apoiada pelo controle assimétrico sobre os recursos econômicos, a atividade de trabalho, o excedente gerado e os fluxos de renda (Tilly, 1998; Tilly; Tilly, 1998; Roemer, 1988; Wright, 2005; Figueiredo Santos, 2015a; 2015b). 


\section{Esquema de classe social}

A construção de um modelo de classe baseado na estrutura do emprego fornece uma delimitação realística, socialmente identificável e de bom alcance das fontes de poder social e vantagens materiais existentes. A noção de emprego focaliza a atividade empreendida e sua relação com as demais atividades dentro da organização social do trabalho de modo a caracterizar a existência de uma estrutura do emprego. Os empregos possuem características específicas e uma determinada localização, em termos técnicos e sociais, numa estrutura interdependente de empregos cujas propriedades emergentes são relativamente autônomas das pessoas que ocupam essas posições (Granovetter, 1981; Sørensen; Kalleberg, 1981). Um emprego corresponde a um conjunto de direitos e obrigações, enfeixados em papéis ou posições, que conectam em transações de trabalho um agente aos outros membros da mesma organização. As transações de trabalho envolvem transferências de informações e/ou de resultados em que o esforço de ao menos uma parte acrescenta valor ao elemento transferido (Tilly; Tilly, 1998). Os empregos caracterizam o que alguém controla (ativos) e o que essa pessoa faz com o que tem, implicando práticas e relações sociais. Os empregos conectam-se mais claramente com as características típicas da sociedade capitalista e, portanto, refletem melhor os processos sistêmicos, institucionais, organizacionais, ao nível micro da ação, que estabelecem e reproduzem a desigualdade nessa sociedade. Os esquemas de classe baseados em emprego têm se mostrado mais estáveis, comparáveis e robustos para a investigação de relevantes resultados sociais (Wright, 1997; Goldthorpe; McKnight, 2006; Crompton, 2010).

As vantagens de classe do topo social na estrutura do emprego baseiam-se na propriedade de ativos de capital, no controle de conhecimento perito e na relação com o exercício de autoridade dentro da organização do trabalho. $\mathrm{O}$ bloco de posições privilegiadas de classe é composto por capitalista, especialista autônomo, empregado especialista e gerente. A propriedade de ativos de capital possui uma centralidade no funcionamento do sistema social mais amplo e na operação das empresas como núcleos institucionalizados de controle de ativos generativos de valor e receptores primários do excedente social. O exercício de autoridade envolve uma diferenciação de classe entre os empregados em razão do papel da dominação dentro das relações de propriedade capitalistas e da capacidade de apropriação por parte das funções gerenciais de uma porção do excedente social obtido pela organização. O especialista tem uma posição estratégica na operação dos sistemas peritos que organizam e medeiam a relação dos atores e das organizações com grandes áreas dos ambientes materiais e sociais. Ocupa localização privilegiada na organização da produção, como controlador de conhecimento, e na operação dos mercados de trabalho, como beneficiário de capacidade escassa e reserva de oportunidades (Figueiredo Santos, 2005; 2014a).

O trabalhador típico representa a categoria majoritária e de grande densidade social. Possui o controle pessoal do ativo de capacidade de trabalho, mas 
é constrangido a ceder ao empregador parte dos frutos do emprego produtivo dessa capacidade. Como está tipicamente inserido em processos de interdependência assimétrica na organização social do trabalho, retém certo poder de intervenção individual e coletiva em relação à apreciação ou depreciação de valor da capacidade de trabalho. Os empregados qualificados (qualificação sem privilégios) e os supervisores (autoridade limitada) estão numa "área cinza" de situações intermediárias ou ambíguas de classe que podem ser aproximadas de uma configuração ampliada de classe trabalhadora.

A promoção de uma extensão teórica do princípio de exclusão do controle de ativos ou recursos econômicos valiosos fundamenta e unifica a noção de $p^{-}$ sições de classe destituidas e, ao mesmo tempo, serve para especificar os processos que geram destituição. Os mecanismos de exclusão, restrição e depreciação de ativos, nas suas várias manifestações, como ativos de capital, terra, qualificação, emprego e força de trabalho, contribuem para compor um grande, diversificado e heterogêneo agregado de posições de classe destituídas na base da estrutura social. O critério de classe é a "destituição, restrição ou depreciação" relativa à posse, ao uso e ao valor de ativos produtivos. Esse bloco é composto pelo trabalhador elementar, autônomo precário, empregado doméstico e agrícola precário. Apresenta-se de modo sucinto a ideia delineadora de cada categoria. Autônomo precário: destituído de ativos de capital ou qualificações; atividade reproduzida nos interstícios do mercado de produtos e serviços. Empregado doméstico: faz um trabalho isolado e disperso de produção de valores de uso para a reprodução de uma unidade domiciliar que não a sua; há uma forte assimetria de poderes e direitos na relação de emprego; ocorre uma depreciação estrutural inerente a um trabalho terminal (dead-end). Agrícola precário: caracterizado pela insuficiência de ativos de terra e de estoques vivos; dependência de mercados locais marginais; insegurança em relação aos direitos de propriedade (posseiro). Trabalhador elementar: executa tarefas simples, socialmente demandadas, mas muito desvalorizadas; sofre forte depreciação de valor da sua capacidade de trabalho, por causa da alta assimetria de poderes e direitos nas relações de trabalho (Figueiredo Santos, 2010; 2014a).

\section{Estratégias e limites da análise}

$\mathrm{Na}$ análise das mudanças na distribuição de recompensas no período mais recente uma atenção especial será dedicada à situação do topo social de posições de classe privilegiadas, da classe trabalhadora (típica e ampliada) e da base social de posições destituidas de ativos. São apresentados dois tipos ou conjuntos de resultados empíricos. Sintetizam-se evidências de sentido mais amplo que emergiram de três estudos combinados e complementares, que cobrem o período de 1992 a 2011, mas sem reproduzir dados originais detalhados. Novas estimativas atualizadas são apresentadas da evolução no período de 2002 a 2014 dos desvios absolutos da renda em relação à mediana geral no sentido de maior ou menor desigualdade. Abordam-se sempre as alterações na renda mediana das 
categorias, apoiado no entendimento de que essa medida sumária retrata melhor os efeitos das mudanças para a maioria dos membros de cada grupo. O estudo menciona medidas de diferenças observadas e de diferenças ajustadas por regressão quantílica (Hao; Naiman, 2007). As diferenças observadas (brutas) refletem a situação das pessoas concretas inseridas nos contextos ou categorias sociais. As estimativas de efeitos ajustados ou controlados permitem revelar a estrutura subjacente aos dados observados e aferir os efeitos intrínsecos do ordenamento ou mecanismo que opera em uma categorização social. Em certas situações são citados efeitos tanto absolutos quanto relativos. As diferenças absolutas medem as distâncias por subtração ou adição entre os rendimentos. As diferenças relativas medem uma razão ou proporção entre os rendimentos. Desigualdade relativa e absoluta são dois conceitos diferentes de desigualdade e não dois modos de medir a mesma coisa (Medeiros, 2012).

$\mathrm{Na}$ análise da mudança e da variação na distribuição total da renda, os levantamentos domiciliares, como a Pesquisa Nacional por Amostra de Domicílios (Pnad), possuem limitações. Estudos recentes baseados em informações do Imposto de Renda demonstram que essa fonte gera uma subestimação da concentração da renda acima dos $5 \%$ e mesmo dos $10 \%$ mais ricos. A concentração no topo é substancialmente maior do que tem sido estimado e, em termos gerais, ela permanece estável no período recente (Medeiros; Souza; Castro, $2015 a ; 2015 b$ ). Os dados domiciliares corrigidos por informações do Imposto de Renda mostram um patamar de concentração bem maior e um processo de desconcentração bem menor da desigualdade agregada no Brasil. Com a correção para a renda dos $10 \%$ mais ricos, a queda observada do índice de Gini entre 2002 e 2013 se reduz bastante, e o processo descendente se esgota a partir de meados de 2000 (Souza, 2016). O quadro retratado neste artigo, apoiado em dados da Pnad, espelha uma distribuição incompleta ou truncada nos níveis mais elevados da renda. Entretanto, parece razoável considerar que tomada como um conjunto a distribuição mais completa espelhe muito a incompleta nas dimensões cruciais que organizam socialmente a distribuição das recompensas. Os dados e os índices mobilizados na interpretação da distribuição da renda no Brasil focalizam, regra geral, o que se passa com a desigualdade agregada de renda entre indivíduos. O resultado agregado pode ser abordado de modo mais esclarecedor quando se recorre à sua decomposição por categorias de classe e educacionais (Souza; Carvalhaes, 2014). A sociologia está particularmente interessada na desigualdade entre grupos. $\mathrm{O}$ esquema de classe referido neste artigo demarca os grupos ao nível da estrutura do emprego e interessa-se pelos efeitos das suas posições relativas nos fluxos e deslocamentos de renda. Tornam-se observáveis nas categorias desenhadas essencialmente os processos que envolvem, repercutem ou são canalizados através da estrutura do emprego. Não estão sendo diretamente tratados aqui, cabe ponderar, aspectos cujas conexões se distanciam da divisão social do trabalho, assim como questões mais estritamente atinentes à desigualdade agregada total e ao $1 \%$ mais rico da distribuição da renda entre indivíduos. 


\section{Mudanças de renda entre as classes}

A análise deve naturalmente ser introduzida pela evolução temporal da composição da estrutura social e do peso relativo dos grupos desigualmente recompensados. O topo privilegiado da estrutura social aumentou essencialmente por conta da expansão dos especialistas. A base de posições destituídas decresceu com a retração de todas as categorias que a compõem. A expansão do trabalhador típico, cuja renda está próxima da mediana, ocorreu a partir de meados da década de 2000. Os estratos agrícolas estão continuamente em retração (Figueiredo Santos, 2015b).

No conjunto do período pós-1992 os especialistas e empregados qualificados sofrem os maiores retrocessos de renda, em termos tanto absolutos quanto relativos, em comparação à mediana geral e às mudanças nas medianas dos demais grupos. Os principais detentores de ativos de capital se saem melhor, porém não acompanham a elevação da mediana geral. Os progressos maiores da renda mediana se dão na base da estrutura social, na comparação tanto com 1992 quanto com 1995, exceto para o agrícola precário. Entretanto, a renda particularmente do trabalhador típico eleva-se menos do que a mediana geral em ambas as comparações, o que implica um decréscimo relativo. No período mais recente pós-2002 constatou-se uma elevação da renda absoluta dos principais detentores ativos de capital (capitalista e pequeno empregador). Já os especialistas (empregados e autônomos) experimentam um decréscimo de renda mediana. A renda do trabalhador típico progride basicamente no subperíodo de 2006 em diante. Na grande maioria da base social destituída as melhoras já aparecem em 2002 e continuam dai em diante (Figueiredo Santos, 2015b).

Ao olhar para os desvios percentuais da renda de cada categoria em relação à mediana geral, as mudanças nas rendas observadas (não ajustadas) sinalizaram uma redução das distâncias de renda composta mais por perdas do topo do que por ganhos da base definidos pela natureza do emprego. O agrupamento de emprego privilegiado, de maior renda, teve mais perdas, mas aumentou na população; o agrupamento de emprego destituído, de menor renda, teve mais ganhos, porém diminuiu de peso demográfico. Ao reduzirem as distâncias de renda em face do centro da distribuição (mediana geral) ambos os movimentos em conjunto favoreceram a queda da desigualdade (Figueiredo Santos, 2015a).

A desconcentração das rendas ajustadas, que capta de modo mais puro o efeito do mecanismo social, reflete-se no fato de o topo privilegiado ter perdido e a base destituída ter ganhado renda em termos tanto absolutos quanto relativos. A queda das diferenças absolutas, no entanto, foi menos marcante. Ocorreram igualmente reduções nas distâncias de renda entre categorias mais próximas ou menos distantes sociologicamente entre si. As dimensões de capital, autoridade e credencial da estrutura social atuaram de modo bem diferenciado. As perdas mais pronunciadas estiveram vinculadas às credenciais mais elevadas das posições de especialistas. A dimensão de capital mostrou um padrão de au- 
mento das vantagens absolutas combinado com certa queda restrita das diferenças relativas. Os principais detentores de ativos de capital conseguiram proteger ou mesmo expandir as suas rendas em um contexto de progressiva diminuição da desigualdade de renda entre os indivíduos. No curso do período a renda do pequeno empregador se aproximou do bloco privilegiado. Na comparação com 1992 a vantagem de renda do gerente em relação ao trabalhador típico aumentou sem e com o controle da educação. Na década de 2000 as vantagens do supervisor aumentaram tanto em termos absolutos quanto relativos. Dimensões fundamentais ao funcionamento da sociedade de classes, como são as relações de propriedade e autoridade, mostraram efeitos mais persistentes num contexto de queda significativa das diferenças de renda entre os indivíduos. As vantagens de possuir capital (capitalista e pequeno empregador) e exercer autoridade (gerente e supervisor), no entanto, podem não ter amortecido tanto a queda da desigualdade agregada, em razão da diminuição do peso global dessas categorias na estrutura do emprego, num quadro de expansão de outros grupos. A ampliação dos empregos de especialistas no topo da estrutura social, combinada com a redução do padrão de renda dessas categorias, impactou na diminuição das discrepâncias de renda, pois a composição e as vantagens dos grupos privilegiados se tonaram mais dependentes do controle e do emprego de insumos educacionais que estiveram perdendo valor. Entretanto, nas estimativas dos efeitos de classe, ao ser introduzido o controle estatístico da educação, ocorre no curso do tempo o aumento das discrepâncias ajustadas de renda das categorias da base em relação ao polo superior. Embora esse controle introduza problemas nas estimativas dos efeitos, pois as categorias de especialistas, majoritárias no topo social, se caracterizam por controlar credenciais educacionais, esse resultado sugere que se não tivessem ocorrido reduções na dispersão da escolaridade e/ou depreciação do valor econômico da escolaridade, as vantagens do bloco privilegiado seriam bem maiores na atualidade. As mudanças de renda foram menores justamente entre as dimensões da estrutura social que foram menos afetadas por alterações na distribuição ou dispersão da educação e os seus efeitos diretos e indiretos na renda (Figueiredo Santos, 2015a; 2015b).

Todos os cenários desenhados pelo jogo de controles estatísticos mostram que diminuiu sensivelmente a vantagem de renda de possuir mais escolaridade. Os dados mostram adicionalmente que as vantagens associadas à posse de escolaridade, com o controle do acesso à classe social, regridem em todos os três níveis da distribuição de renda analisados. Estima-se então um efeito puramente direto da educação, ou seja, sem a contribuição indireta da educação como critério de acesso aos bons empregos que exigem escolaridade. Esse retrocesso relativo de renda é particularmente forte no nível superior. No topo do ordenamento da renda ( $20 \%$ mais ricos) as vantagens absolutas de renda dos graus de escolaridade mais elevados, em relação aos que não possuem escolaridade fundamental completa, passaram a equivaler a apenas $47 \%$ (12 a 14 anos) e a $63 \%$ (15 anos ou mais) do que já foram no ano de 1992 (Figueiredo Santos, 2015b). 
As alterações distributivas que se deram na dispersão e assimetria da renda dentro das classes sociais são agregadas à análise. Mudanças de dispersão ocorrem quando os membros do grupo são redistribuídos ao longo da escala de rendimentos que vai do centro aos extremos superiores ou inferiores da distribuição (Handcock; Morris, 1999, p.41). O grupo torna-se menos desigual ou mais homogêneo na medida em que as rendas mais baixas e/ou mais altas fiquem mais próximas ou menos distantes da mediana. Os deslocamentos de renda dentro das duas categorias de especialistas, representativas da classe média, tenderam a ampliar as rendas mais altas. O elevado patamar de discrepância interna do gerente regride. Constata-se claramente para o trabalhador típico, o trabalhador elementar e o empregado doméstico uma tendência de contração da renda nos percentis mais elevados que ficaram menos distantes da mediana de cada categoria. O trabalhador típico passa por uma contração relevante dos valores extremos tanto superiores quanto inferiores à mediana. A ocorrência de contração da renda dentro dos grupos representa um fator contribuinte para a redução da desigualdade agregada (Figueiredo Santos, 2014b).

A noção estatística de assimetria refere-se ao desequilíbrio entre a dispersão abaixo e acima do centro da distribuição. Regra geral, a distribuição da renda fica desequilibrada na direção dos valores superiores ao centro. A assimetria tende a aumentar na maioria dos grupos mais privilegiados. Os pequenos empregadores experimentam uma queda da assimetria. Os padrões de assimetria de gerentes e empregados especialistas se aproximaram, com a queda no primeiro grupo e o aumento no segundo. Tanto os trabalhadores destituídos quanto os trabalhadores típicos ficaram mais equilibrados na distribuição interna da renda. O desequilíbrio na direção das rendas superiores à mediana se reduziu particularmente entre as categorias de trabalhadores com maior densidade social (Figueiredo Santos, 2014b).

\section{Fatores de segmentação e de status social}

Diferenciações da atividade econômica e segmentações do mercado de trabalho revelaram-se como contextos sociais influentes nos deslocamentos de renda. Os setores de atividade econômica mostraram movimentos com sentidos inversos que levaram à diminuição da desigualdade setorial de renda. Entre os seis setores considerados, os dois de pior padrão de renda tiveram bom desempenho no período, com destaque para a indústria extrativa. Os dois segmentos de renda mais elevada tiveram rebaixamentos absolutos de renda mediana. Os serviços produtivos foram os que mais perderam nesse processo predominante de convergência de renda entre os setores. As discrepâncias de rendas ajustadas confirmaram que o processo não dependeu das diferenças de composição de classe e educacional entre os setores. Reduções nas desigualdades espaciais de renda, ligadas aos territórios e particularmente às hierarquias urbanas, contribuíram para a diminuição da desigualdade de renda entre e dentro dos grupos sociais. Em todas as regiões a renda mediana cresceu, mas o Sudeste apresentou 
o pior desempenho e o Centro-Oeste, o melhor. A diminuição da vantagem de renda do Sudeste em comparação ao Nordeste se manifestou com mais força nas diferenças relativas ajustadas. A distribuição e os efeitos dos demais determinantes da renda controlados não afetou o resultado. Preponderou no geral certa tendência de redução das discrepâncias em face do Nordeste, excetuando o Centro-Oeste. Estudo recente pondera que a desigualdade entre regiões diminui a partir de 1998, mas somente no setor não agrícola. A principal contribuição para a redução da desigualdade regional veio da queda da vantagem relativa de São Paulo (Hoffmann; Oliveira, 2014, p.202).

A perda relativa de renda do Brasil metropolitano, tanto no critério absoluto quanto no relativo, mostrou-se fortemente intrínseca à dimensão socioespacial, pois independe da composição e dos efeitos de outros determinantes da renda. Os fatores espaciais estão contribuindo para tornar os grupos internamente menos heterogêneos na medida em que padrões de recompensas estão variando menos conforme a localização espacial. Na medida em que as posições privilegiadas de classe estão mais concentradas nesses espaços as vantagens relativas desses grupos e desses territórios foram mutuamente afetadas. Confirmou-se a expectativa sociológica de que os integrantes dos grupos são afetados pelos locais em que residem e os segmentos a que se vinculam para os quais foram diferenciadamente alocados. As características socialmente padronizadas desses contextos representam estruturas de oportunidades que incrementam ou restringem os fluxos de renda e os padrões de vida dos seus ocupantes (Figueiredo Santos, 2015b).

Contemplou-se no quadro composto o foco sociológico no efeito intrínseco ou propriedade emergente da categorização de status social, subjacente aos processos sociais, e o retrato descritivo das discrepâncias de renda entre os indivíduos concretos que estão inseridos nessas divisões sociais. As desigualdades de rendas entre os grupos de status de raça e de gênero evoluíram sob o impacto de processos bem distintos. Embora a desigualdade racial tenha caído em termos brutos, mostrando que no agregado os indivíduos ficaram menos desiguais, mantiveram-se fortes (ou mesmo foram fortalecidos) os processos mediados pelo acesso desigual a contextos e recursos valiosos que têm historicamente sustentado a desigualdade racial. Em relação à desigualdade de gênero os fatores mediadores passaram a favorecer ou a desfavorecer menos à mulher o que ajudou a comprimir um tanto a vantagem masculina. Se não fossem esses fatores, ou seja, se não fosse uma mudança nos efeitos mediados, o efeito direto da categorização de gênero teria aumentado a vantagem masculina. $\mathrm{O}$ efeito direto da atribuição de valor de gênero como princípio organizador das relações sociais mostrou uma força persistente tanto dentro dos contextos sociais quanto independentemente deles.

Os efeitos diretos e indiretos se combinam de diferentes maneiras ao promoverem mudanças de renda entre os grupos de status de raça e de gênero. $\mathrm{O}$ 
efeito direto ou de tratamento diz respeito ao julgamento de valor social atribuído por ser membro da categoria e o efeito indireto envolve a implicação do marcador de status social no acesso desigual a recurso ou contexto valioso. $\mathrm{Na}$ categorização racial a desigualdade de acesso se fortaleceu ou permaneceu forte, enquanto caiu a de tratamento; na categorização de gênero, a desigualdade de acesso diminuiu, mas a de tratamento aumentou. As pessoas concretas inseridas nessas categorias ficaram menos desiguais, pois foi mais favorável o resultado agregado da combinação entre efeitos diretos (tratamento) e indiretos (acesso). A distinção analítica entre desigualdade de acesso e de tratamento mostrou-se chave para entender as mudanças de renda entre os grupos de raça e gênero (Figueiredo Santos, 2015b).

\section{Evolução dos desvios absolutos da renda}

A descrição e análise da evolução das discrepâncias de renda associadas à estrutura social do emprego, como transparece na exposição realizada, demanda a combinação de diferentes critérios (rendas observadas e ajustadas; distâncias absolutas e relativas) e termos de comparação (centro da distribuição; base e topo social; pares informativos). Uma informação útil sobre o comportamento da desigualdade pode ser extraída dos desvios da renda em relação ao centro da distribuição (Amiel; Cowell, 1999, p.10). Na óptica da desigualdade absoluta optou-se por realizar uma comparação entre os desvios absolutos da renda mediana de cada categoria em relação ao centro da distribuição representado pela mediana geral de todos os grupos. Em dois gráficos são apresentados dados atualizados cobrindo a evolução dos desvios absolutos (diferenças por subtração) em relação à mediana da renda do trabalho principal deflacionada e expressa em reais de 2014 (valor junto ao ano). Utilizaram-se as medianas preditas que foram ajustadas pelos controles estatísticos de gênero, raça, região geográfica, setor de atividade econômica, dimensão da área urbana, tempo de trabalho e horas trabalhadas. Os valores ajustados em Reais formam obtidos com o procedimento PREDXCAT criado por J. M. Garrett para o ambiente do programa Stata. Estimaram-se então efeitos mais puros ou intrínsecos dos empregos, ou seja, independentes das dimensões controladas que possuem influências específicas na renda. São apresentados separadamente os dados das categorias cujos desvios estão acima da mediana geral de todas as categorias (Gráfico l) e daquelas em que os desvios ficam abaixo da mediana geral (Gráfico 2).

As categorias estão ordenadas no Gráfico 1 dos desvios positivos maiores aos menores. Percebe-se claramente uma redução dos desvios absolutos da renda das quatro categorias que conformam o topo dos empregos mais privilegiados. As tendências devem ser divisadas atentando para as flutuações no período e não somente olhando para o resultado no final da série em 2014. Deve-se levar em contra que no ano inicial (2002) o topo está numa situação mais elevada o que cria linhas descendentes para todos. Se a base de comparação for 2003 as alterações descendentes são bem menos marcantes ou se invertem para 
o especialista autônomo e o gerente. Além disso, a partir de 2006 os desvios voltam a aumentar, o que se ajusta ao diagnóstico de esgotamento da queda da desigualdade agregada em meados da década de 2000 (Souza, 2016). O resultado negativo do capitalista ocorre após uma retomada ascendente da renda que durou de 2006 a 2011, o que testemunha o potencial dos ativos de capital. O empregado especialista mostra um descenso mais contínuo e flutuações ou movimentos reativos mais leves. O pequeno empregador confirma o movimento que tem aproximado o seu padrão de renda do topo privilegiado. Entre os três grupos inseridos de modo limitado nas dimensões de capital (autônomo com ativos), autoridade (supervisor) e qualificação escassa (empregado qualificado), melhores posicionados no final do período, destaca-se a trajetória ascendente do supervisor particularmente a partir de 2008. As reduções dos desvios absolutos de renda das posições no topo social, em que mais renda está concentrada, espelham um processo de redução da desigualdade. Parte do que se observa, no entanto, pode refletir a visão de uma distribuição incompleta que subestima a concentração da renda ao nível dos $5 \%$ e mesmo dos $10 \%$ mais ricos.

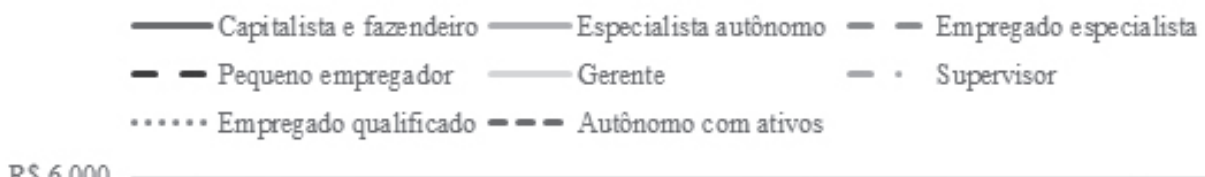

RS 6.000
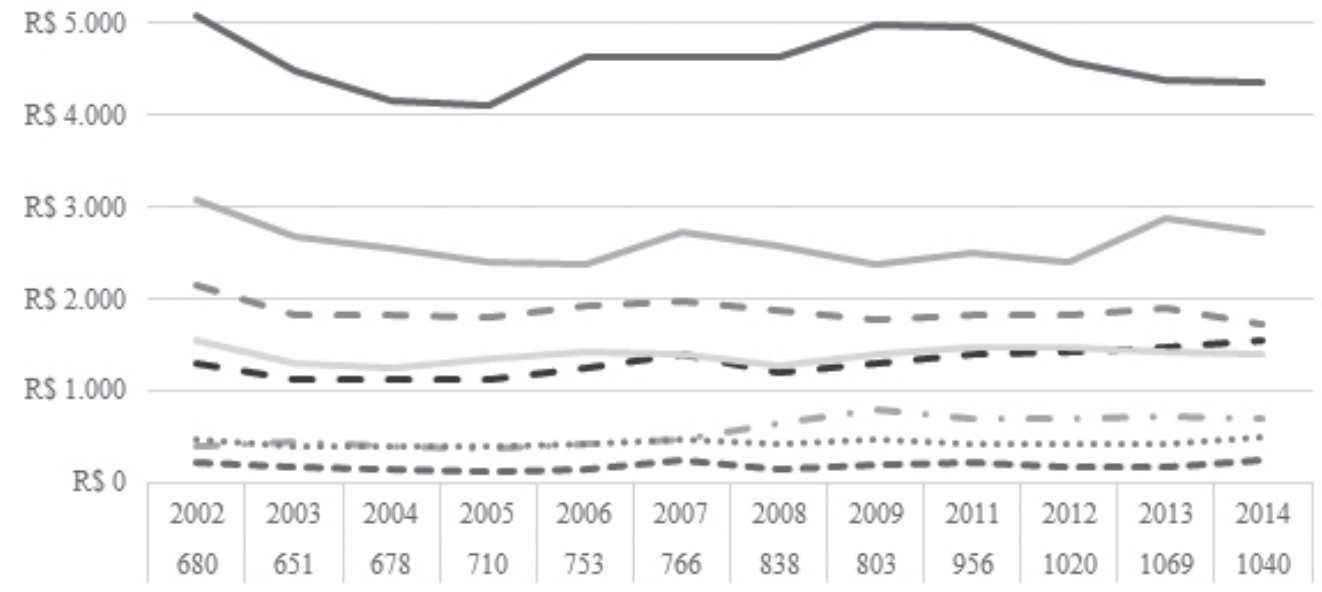

Gráfico 1 - Desvios absolutos positivos em relação à mediana geral por categorias de classe. Brasil, 2002-2014. 


\section{- Trabalhador tipico - Empregado doméstico - - Autônomo precírio -Trabalhador elementar - - Autônomo agricola - Agricola precário}

RS 100

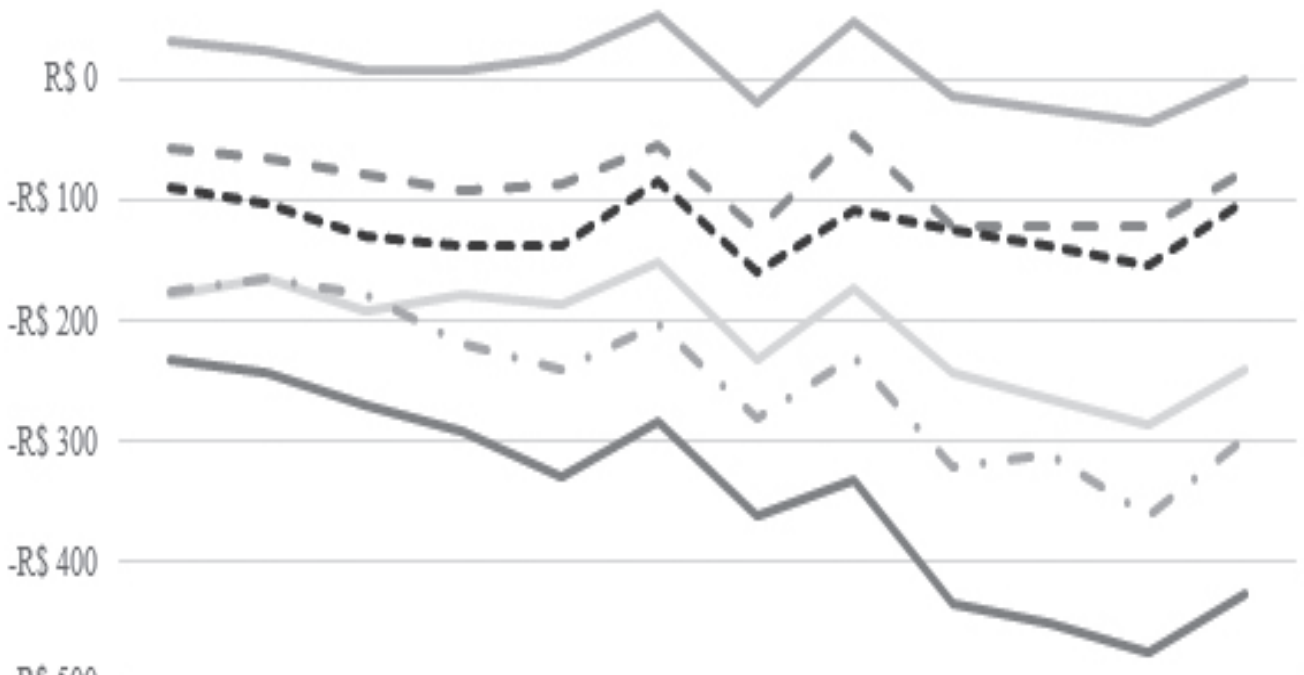

-RS 500

-RS 600

\begin{tabular}{c|c|c|c|c|c|c|c|c|c|c|c|}
\hline 2002 & 2003 & 2004 & 2005 & 2006 & 2007 & 2008 & 2009 & 2011 & 2012 & 2013 & 2014 \\
\hline 680 & 651 & 678 & 710 & 753 & 766 & 838 & 803 & 956 & 1020 & 1069 & 1040 \\
\hline
\end{tabular}

Gráfico 2 - Desvios absolutos negativos em relação à mediana geral por categorias de classe. Brasil, 2002-2014.

No Gráfico 2 as categorias estão ordenadas dos desvios menores aos maiores. Uma linha decrescente significa aumento do distanciamento negativo em relação à renda mediana geral. No conjunto das categorias ocorre certo padrão comum de evolução temporal, pois regra geral os desvios aumentam gradualmente de 2002 até 2006, diminuem em 2007, elevam-se de 2006 a 2008, caem em 2009, depois voltam a aumentar gradualmente até 2013 para diminuírem um pouco em 2014. Esse padrão é um pouco diferenciado para cada categoria. No início do período o trabalhador típico está acima da mediana geral, enquanto as posições destituídas e o autônomo agrícola estão abaixo desse patamar em qualquer ponto no tempo. Descontadas as ligeiras flutuações para cima e para baixo a categoria acompanha os movimentos da mediana durante todo o período. Em todas as demais categorias a tendência é de aumento dos desvios absolutos. Nesse bloco o empregado doméstico tem o menor desvio ao longo de todos os anos, pois a sua linha está sempre acima das outras. Os desvios do autônomo precário suplantam os do emprego doméstico, mas os dois seguem oscilações 
semelhantes. Em razão possivelmente do peso do trabalhador manual agrícola na composição da categoria, o trabalhador elementar apresenta tendência de ampliação similar aos estratos agrícolas, mas com patamares menores de desvio. O precário agrícola distancia-se ainda mais de todos os demais em particular nos anos mais recentes. No conjunto percebe-se que depois de 2009 os desvios negativos estão num patamar maior. Olhando-se para a base social a desigualdade absoluta então aumenta nesse critério de desvios do centro da distribuição. Quando se olha para o topo social no mesmo critério vê-se que a desigualdade absoluta diminui na comparação com 2002. O topo naturalmente controla mais renda, mas a base possui peso demográfico muito maior. Entretanto, se fosse adotado o critério de desvio percentual (diferença dividida pela mediana), referido agora num breve contraste, emergiria um quadro diferenciado embora relativamente compatível com o comportamento da desigualdade absoluta (estimativas não reproduzidas aqui). $\mathrm{O}$ topo social mostra uma redução bem maior dos desvios relativos (\%) da renda em relação ao centro da distribuição. Os dois estratos agrícolas mostram aumento das distâncias relativas. Reduzem-se ao final do período as discrepâncias do trabalhador elementar, do autônomo precário e do empregado doméstico, porém depois de experimentarem elevação em vários momentos na trajetória. Os dados atualizados dos desvios absolutos adicionam uma nova faceta ao quadro delineado que demanda para uma composição mais completa a combinação de critérios e termos de comparação como se procurou explorar no curso dessa análise das relações entre emprego, estratificação e desigualdade no Brasil. Embora as dimensões e categorias da estrutura social mostrem alterações diferenciadas e nuançadas, predominando tendência de redução da desigualdade, a subordinação da distribuição da renda ao ordenamento de classe da sociedade brasileira mantém-se robusta em meio às mudanças ocorridas.

\section{Referências}

AMIEL, Y.; COWELL, F. A. Thinking about Inequality: personal judgment and income distributions. Cambridge: Cambridge University Press, 1999.

CROMPTON, R. Class and employment. Work, Employment and Society, v.24, n.1, p.9-26, 2010.

FIGUEIREDO SANTOS, J. A. Uma classificação socioeconômica para o Brasil. Revista Brasileira de Ciências Sociais, São Paulo, v.20, n.58, p.27-45, 2005.

Comprehending the class structure specificity in Brazil. South African Review of Sociology, v.41, n.3, p.24-44, 2010.

Esquema de classe para abordar a desigualdade de saúde no Brasil. In: RO-

SENBERG, F. (Org.) Classes sociais, território e saúde: questões metodológicas e políticas. Rio de Janeiro: Editora Fiocruz, 2014a. p.39-59. Disponível em: <http://www. forumitaborai.fiocruz.br/node/896>. 
FIGUEIREDO SANTOS, J. A. Classe média e mudanças de renda no Brasil. Revista Brasileira de Sociologia, v.2, n.4, p.84-107, 2014 b.

Classe social e deslocamentos de renda no Brasil. Dados, Rio de Janeiro, v.58, n.1, p.79-110, 2015a.

Mudanças de renda no Brasil: fatores espaciais, setoriais, educacionais e de status social. Sociedade e Estado, Brasília, v.30, n.3, 2015 b.

GOLDTHORPE, J.; MCKNIGHT, A. The economic basis of social class. In: MORGAN, S. et al. (Ed.) Mobility and inequality. Stanford: Stanford University Press, 2006.

GRANOVETTER, M. Toward a sociological theory of income differences. In: BERG, I. (Ed.) Sociological perspectives on labor markets. New York: Academic Press, 1981.

HANDCOCK, M.; MORRIS, M. Relative distribution methods in social sciences. New York: Springer, 1999.

HAO, L.; NAIMAN, D. Quantile regression. Thousand Oaks: Sage, 2007.

HOFFMAAN, R.; OLIVEIRA, R. The evolution of income distribution in Brazil in the agricultural and the non-agricultural sectors. World Journal of Agricultural Research, v.2, n.5, p.192-204, 2014.

MEDEIROS, M. Medidas de desigualdade e pobreza. Brasília: Editora UnB, 2012.

MEDEIROS, M.; SOUZA, P.; CASTRO, F. A. O topo da distribuição de renda no Brasil: primeiras estimativas com dados tributários e comparação com pesquisas domiciliares (2006-2012). Dados, Rio de Janeiro, v.58, n.1, p.7-36, 2015 a.

MEDEIROS, M.; SOUZA, P.; CASTRO, F. A. A estabilidade da desigualdade de renda no Brasil, 2006 a 2012: estimativa com dados do imposto de renda e pesquisas domiciliares. Ciência é Saúde Coletiva, Rio de Janeiro, v.20, n.4, p.971-85, 2015 b.

ROEMER, J. Free to lose: an introduction to Marxist economic philosophy. Cambridge: Harvard University Press, 1988.

SØRENSEN, A.; KALLEBERG, A. An outline of a theory of the matching of persons to jobs. In: BERG, I. (Ed.) Sociological perspectives on labor markets. New York: Academic Press, 1981.

SOUZA, P. Os ricos e a desigualdade no Brasil ao longo de nove décadas. Trabalho inédito, 2016.

SOUZA, P.; CARVALHAES, F. Estrutura de classes, educação e queda da desigualdade, 2002-2011. Dados, Rio de Janeiro, v.57, n.1, p.101-28, 2014.

TILLY, C. Durable inequality. Berkeley: University of California Press, 1998.

TILLY, C.; TILLY, C. Work under capitalism. Boulder: Westview Press, 1998.

WRIGHT, E. O. Class counts: comparative studies in class analysis. Cambridge: Cambridge University Press, 1997.

Foundations of a neo-marxist class analysis. In: analysis. Cambridge: Cambridge University Press, 2005. p.4-28.

(Ed.) Approaches to class 
RESUMO - As relações entre divisão social do trabalho e estratificação social são consideradas como nexos explicativos-chave das mudanças recentes na distribuição de renda no Brasil. Destaca-se o papel das divisões de classe ao nível da estrutura do emprego, ao qual se agregam grupos de status, fatores de segmentação e credenciais educacionais. Os determinantes em questão captam alterações em dimensões socialmente organizadas da distribuição das recompensas. Constatam-se reduções nas desigualdades espaciais, setoriais e educacionais. As desigualdades de status social caem mostrando sinais contraditórios. Os condicionamentos de classe da renda se mantêm robustos, mas apresentando efeitos diferenciados e nuançados em meio às reduções na desigualdade agregada de renda.

PALAVRAS-CHAVES: Desigualdade, Classe, Emprego, Estratificação, Renda.

ABSTRACT - The relationships between the social division of labor and social stratification are regarded as the key explanatory nexus of recent changes in income distribution in Brazil. The paper highlights the role of class divisions at the level of the job structure, to which are added status groups, segmentation factors and educational credentials. The determinants in question capture changes in the socially organized dimensions of the distribution of rewards. Reductions in the spatial, sectorial and educational inequalities are acknowledged. The inequalities in social status wane, showing contradictory signals. The class conditionings on income remain robust, but show differentiated and nuanced effects amidst the reductions in aggregate income inequality.

KEYWORLDS: Inequality, Class, Employment, Stratification, Income.

José Alcides Figueiredo Santos é professor associado da Universidade Federal de Juiz de Fora, com doutorado em Sociologia pelo Instituto Universitário de Pesquisas do Rio de Janeiro e pós-doutorado na Universidade de Wisconsin-Madison.

@ - josealcidesf@yahoo.com.br.

Luiz Vicente Fonseca Ribeiro é mestre e doutorando em Ciências Sociais pela Universidade Federal de Juiz de Fora. @ - tukoop@gmail.com.

Recebido em 15.5.2016 e aceito em 23.6.2016.

I, II Universidade Federal de Juiz de Fora, Juiz de Fora/Minas Gerais, Brasil. 